\title{
THE QUALITY OF PHOTOGRAPHS PRODUCED BY THE NON-MYDRIATIC FUNDUS CAMERA IN A SCREENING PROGRAMME FOR DIABETIC RETINOPATHY: A 1 YEAR PROSPECTIVE STUDY
}

\author{
C. J. HEAVEN, J. CANSFIELD and K. M. SHAW \\ Portsmouth
}

\begin{abstract}
SUMMARY
A prospective study was performed on the quality of photographs produced by the non-mydriatic fundus camera used in a hospital-based screening programme for diabetic retinopathy. In 1 year 981 binocular patients were photographed. A photograph of acceptable quality was obtained from $90.5 \%$ of eyes and $84.4 \%$ of patients had an acceptable photograph of both eyes. The photograph of the second eye was more often unacceptable than that of the first. This tendency was significant in females $(p=0.0196)$ and when considering the sexes together $(p=0.0044)$, but not significant in males $(p=0.1042)$. Photographs of unacceptable quality were obtained significantly more often in patients aged over 55 years for both right and left eyes $(p=0.0001)$. An overall improvement in photographic quality might be achieved by allowing full recovery of flash-induced pupil constriction before taking the second photograph and by dilating those aged over 55 years.
\end{abstract}

Diabetic retinopathy is a condition well suited to screening. ${ }^{1}$ This screening may be performed by doctors with hospital diabetic clinics, by general practitioners or by optometrists. $^{2-5}$ However, more recently the nonmydriatic fundus camera has been proposed as an effective alternative. ${ }^{6-15}$ Taylor et al. ${ }^{12}$ found the camera to be at least as good as ophthalmoscopy with mydriasis in detecting retinal neovascularisation and to be superior in detecting exudative maculopathy. Buxton et al.$^{15}$ have reported that the camera has a sensitivity and specificity similar to the other screening modalities in the detection of visionthreatening retinopathy.

We have established within our hospital a screening programme for diabetic retinopathy using this camera. The programme is run jointly by the Diabetic Day Unit

From: Department of Ophthalmology and the Diabetic Day Unit, Queen Alexandra Hospital, Portsmouth, UK.

Correspondence to: Mr. C. J. Heaven, DO, FRCS(Edin), FRCOphth, Department of Ophthalmology, Queen Alexandra Hospital, Cosham, Portsmouth PO6 3LY, UK. and the Department of Ophthalmology. The details of this screening programme have been reported elsewhere. ${ }^{16}$ The non-mydriatic camera has been criticised for the supposed poor quality of photographs it produces. We have therefore conducted a 1 year prospective study on the quality of the photographs produced by the camera during the running of the above screening programme. The study had three aims:

1. To quantify the overall standard of photographic quality attained.

2. To test the hypothesis that poorer-quality photographs tend to be obtained from the eye photographed second, due to a flash-induced pupil constriction following photography of the first eye.

3. To test the hypothesis that poorer-quality photographs tend to occur with increasing age.

The manner of data collection and the statistical analysis were such as to address (1) and (3) in particular.

\section{PATIENTS AND METHODS}

The period of the study was 1 year: January 1991 to January 1992. Patients are recruited to the diabetic retinopathy screening programme from the hospital diabetic clinic. The camera used was a Canon CR3 45NM. Its design replaces the bright visible viewing light used in a standard fundus camera with an infrared-sensitive video camera. The view of the ocular fundus displayed on a built-in screen can thus be aligned without inducing pupil constriction. The $45^{\circ}$ field is centred on the fovea and includes the optic disc, the main temporal vascular arcades and the entire macula.

Photographs were taken by a nurse technician. This was done in a darkened room to allow some degree of physiological pupil dilatation but no mydriatic eye drops were used. The right eye was, by convention, always photographed first. An interval of several minutes was allowed before obtaining the second photograph from the left eye. This was to permit pupil recovery from the initial flash. 
Table I. The number of photographs in each quality grade and age group: males (525 patients, 1050 eyes)

\begin{tabular}{lrrrrrrrr}
\hline \multirow{2}{*}{$\begin{array}{l}\text { Photograph } \\
\text { quality } \\
\text { grade }\end{array}$} & $<25$ & $25-34$ & $35-44$ & $45-54$ & $55-64$ & $65-74$ & $\geqslant 75$ & Total \\
\hline 1 & 28 & 71 & 67 & 53 & 71 & 13 & 0 & 303 \\
2 & 24 & 38 & 53 & 87 & 122 & 81 & 16 & 421 \\
3 & 11 & 23 & 25 & 31 & 63 & 56 & 15 & 224 \\
4 & 3 & 4 & 5 & 10 & 24 & 33 & 8 & 87 \\
5 & 0 & 3 & 0 & 1 & 5 & 3 & 3 & 15 \\
Total & 66 & 139 & 150 & 182 & 285 & 186 & 42 & 1050 \\
\hline
\end{tabular}

The colour Polaroid prints obtained were attached to a report form which carried patient identification details, age, date of diabetes diagnosis, type of diabetes treatment and corrected or pinhole visual acuities. Form and photographs were then forwarded to the Department of Ophthalmology for reading by the registrar designated to the screening programme. This person was required to grade the photographic quality of each print according to the following previously reported scheme: ${ }^{8-10,13}$

Grade 1: excellent clarity.

Grade 2: good definition of most retinal detail, easily assessable.

Grade 3: definition limited, assessable with some difficulty.

Grade 4: only gross detail visible.

Grade 5: no detail visible, not assessable.

For the purposes of the screening programme, but not applicable to this study, the type of retinopathy evident on each photograph was determined and an indication given of the need or otherwise for a clinical examination by an ophthalmologist. The report forms were then returned to the Diabetic Day Unit for prospective data collection of the photographic quality gradings. This was done in a manner which preserved the relationship of right and left eyes, age and sex of patients.

McNemar's test was used to determine any tendency for the left (second) photograph to be of poorer quality than the right (first) photograph and $p$ values are corrected for continuity. The chi-squared test was used to determine the influence of age on the photographic quality and $p$ values include a Yates' correction.

\section{RESULTS}

During the year of the study 981 binocular patients (1962

Table II. The number of photographs in each quality grade and age group: females (456 patients, 912 eyes)

\begin{tabular}{|c|c|c|c|c|c|c|c|c|}
\hline \multirow{2}{*}{$\begin{array}{l}\text { Photograph } \\
\text { quality } \\
\text { grade }\end{array}$} & \multicolumn{8}{|c|}{ Age (yr) } \\
\hline & $<25$ & $25-34$ & $35-44$ & $45-54$ & $55-64$ & $65-74$ & $\geqslant 75$ & Total \\
\hline 1 & 50 & 53 & 53 & 56 & 34 & 6 & 0 & 252 \\
\hline 2 & 21 & 38 & 54 & 55 & 121 & 54 & 12 & 355 \\
\hline 3 & 4 & 16 & 21 & 26 & 59 & 69 & 25 & 220 \\
\hline 4 & 4 & 2 & 6 & 6 & 20 & 24 & 6 & 68 \\
\hline 5 & 1 & 0 & 0 & 1 & 5 & 6 & 4 & 17 \\
\hline Total & 80 & 109 & 134 & 144 & 239 & 159 & 47 & 912 \\
\hline
\end{tabular}

Table III. The numbers of right-left photograph quality grading combinations, binocular patients all ages

\begin{tabular}{|c|c|c|c|c|c|c|}
\hline \multirow{2}{*}{$\begin{array}{l}\text { Left eye } \\
\text { photograph } \\
\text { quality grade }\end{array}$} & & \multicolumn{5}{|c|}{ Right eye photograph quality grade } \\
\hline & & 1 & 2 & 3 & 4 & 5 \\
\hline \multirow[t]{2}{*}{1} & Male & 99 & 30 & 10 & 1 & 0 \\
\hline & Female & 82 & 19 & 4 & 2 & 0 \\
\hline \multirow[t]{2}{*}{2} & Male & 44 & 128 & 37 & 6 & 3 \\
\hline & Female & 46 & 103 & 30 & 3 & 0 \\
\hline \multirow[t]{2}{*}{3} & Male & 13 & 32 & 49 & 13 & 2 \\
\hline & Female & 15 & 41 & 50 & 9 & 1 \\
\hline \multirow[t]{2}{*}{4} & Male & 6 & 11 & 17 & 14 & 1 \\
\hline & Female & 2 & 7 & 15 & 12 & 3 \\
\hline \multirow[t]{2}{*}{5} & Male & 1 & 2 & 2 & 4 & 0 \\
\hline & Female & 0 & 3 & 5 & 3 & 1 \\
\hline
\end{tabular}

The right eye was photographed first in all cases.

eyes) were photographed. Four additional patients were uniocular. Table I indicates the photograph quality according to age, for males. Table II is a similar presentation for females. Ideally all photographs should be of either grade 1 or 2. This was achieved in $67.9 \%$ of cases. Grades 4 and 5 we consider to be entirely unsatisfactory. Such grades occurred in $9.5 \%$ of cases.

Table III shows the distribution of right-left photograph quality grading combinations. The commonest combination was that of a grade 2 photograph of each eye. To test the hypothesis that the second (left) photograph will tend to be of poorer quality than the first (right) we determined that a photograph of grade 1,2 or 3 was 'acceptable' and that a photograph of grade 4 or 5 was 'unacceptable'. This we have based on our opinion that vision-threatening retinopathy is likely to be detected on photographs of grades 1,2 or 3 but not on photographs of grades 4 or 5 . This is in accordance with previously published opinion. ${ }^{13}$ The distribution of right-left acceptable and unacceptable photograph combinations is shown in Table IV. Unacceptable photographs occurred significantly more frequently in left as compared with fellow right eyes in females $(p=0.0196)$ and when considering the sexes combined $(p=0.0044)$. For females the difference in proportions was $3.73 \%$, with the $95 \%$ confidence interval (CI) being $0.8 \%$ to $6.65 \%$. For the sexes combined the difference in proportions was $3.16 \%$ (95\% CI $1.06 \%$ to $5.26 \%$ ). In males there was a tendency for the left photograph to be less acceptable than the right but this did not reach significance $(p=0.1042)$. Here the difference in proportions was $2.67 \%$ (95\% CI $-0.31 \%$ to $5.67 \%)$.

Table IV. The numbers of right-left acceptable and unacceptable photograph quality combinations, binocular patients all ages

\begin{tabular}{llcc}
\hline & & \multicolumn{2}{c}{ Right eye photograph quality } \\
\cline { 3 - 4 } $\begin{array}{l}\text { Left eye } \\
\text { photograph quality }\end{array}$ & & Acceptable & Unacceptable \\
\hline Acceptable & Male & 442 & 25 \\
& Female & 390 & 15 \\
& Total & 832 & 40 \\
Unacceptable & Male & 39 & 19 \\
& Female & 32 & 19 \\
& Total & 71 & 38 \\
\hline
\end{tabular}

Acceptable $=$ grades 1,2 and $3 ;$ unacceptable $=$ grades 4 and 5 . 
Table V. The number of acceptable and unacceptable photographs obtained above and below 55 years of age, sexes combined

\begin{tabular}{|c|c|c|c|}
\hline \multirow[b]{2}{*}{ Age group (yr) } & & \multicolumn{2}{|c|}{ Photograph quality } \\
\hline & & Acceptable & Unacceptable \\
\hline \multirow[t]{3}{*}{$\geqslant 55$} & Right & 421 & 60 \\
\hline & Left & 396 & 81 \\
\hline & Total & 817 & 141 \\
\hline \multirow{3}{*}{$<55$} & Right & 482 & 18 \\
\hline & Left & 476 & 28 \\
\hline & Total & 958 & 46 \\
\hline
\end{tabular}

Acceptable $=$ grades 1,2 and $3 ;$ unacceptable $=$ grades 4 and 5.

To test the hypothesis that poorer-quality photographs occur more frequently in older patients we compared the number of acceptable and unacceptable photographs obtained from patients below 55 years of age with those from patients aged 55 years or more. The analysis was made separately for right and left eyes but the sexes were considered together. Table $\mathrm{V}$ illustrates the distribution of photograph quality on this basis. Unacceptable photographs were obtained very significantly more often from eyes of patients aged 55 years or more than from those of under 55 years of age $(p=0.0001$ for both right and left eyes). The difference in proportions for the right eye was $8.87 \%$ (95\% CI $5.50 \%$ to $12.25 \%$ ). The difference in proportions for the left eye was $11.43 \%$ (95\% CI $7.51 \%$ to $15.34 \%)$.

\section{DISCUSSION}

We have established a hospital-based screening programme for diabetic retinopathy using the non-mydriatic fundus camera. The details of this programme and its success in detecting vision-threatening retinopathy have been reported elsewhere. ${ }^{16}$ We believe that the non-mydriatic camera used as part of such a programme offers several advantages over screening by physicians, general practitioners and optometrists. A permanent record of the ocular fundus and any retinopathy present is produced. The expertise of an ophthalmologist is involved in interpreting the photographs whilst the routine operation of the camera can be left to a suitably trained nurse technician. Also the camera may be used as a teaching aid for improving the diagnostic skills of non-ophthalmologists. The camera has, though, been criticised for the quality of the photographs it produces. ${ }^{9}$ This study has enabled us to address this criticism and to quantify the photographic quality achieved by our screening programme.

The quality of photographs produced by the nonmydriatic camera when used in a community setting has been reported previously. ${ }^{13,14}$ However, we believe this to be the first report on the quality of photographs achieved when using the camera as part of an established hospitalbased screening programme. Photographs of an acceptable quality (grades 1, 2 or 3 ) were obtained from $90.5 \%$ of eyes and $84.4 \%$ of patients had an acceptable photograph of both eyes. This compares favourably with the $75 \%$ and $66 \%$ respectively reported by Higgs et al. ${ }^{13}$ when screening in the community. They suggest that poorer- quality photographs might be expected of diabetic patients managed in the community compared with those managed by hospital clinics, due to a higher proportion of elderly type 2 (non-insulin-dependent) diabetic patients in the community. However, the lower photographic standards achieved in their study may also relate to the pilot nature of their screening programme.

When comparing the non-mydriatic camera with other screening modalities Buxton et al ${ }^{15}$ found that the proportion of acceptable-quality photographs varied between $57 \%$ and $84 \%$ depending on the screening centre. Theirs was a short-term study and we believe that we have achieved a higher proportion of acceptable photographs because our programme is well established and continuing. The camera is housed in a dedicated specially adapted room and the staff have become very familiar with its operation.

We found that poorer quality photographs occurred significantly more frequently in those aged over 55 years. We suspect that this is due to cataract and/or the physiological pupil constriction that occurs with ageing. However, this study has not investigated these factors directly.

In females, and when considering the sexes together, unacceptably poor quality photographs occurred significantly more often in the eye photographed second. A similar trend was also present amongst males but did not reach statistical significance. Poorer-quality photographs of the second eye are probably caused by pupil constriction induced when photographing the first eye and mediated via the consensual light reflex. The initial viewing and alignment of the non-mydriatic camera utilises the infrared and does not induce pupil constriction, but the taking of a photograph does involve a bright flash of visible light. The operator should therefore specifically inspect the pupil size of the second eye before proceeding with the second photograph. A further interval should be allowed for pupil recovery if required. This compromise effect upon the second photograph was not observed in a smaller study using the non-mydriatic camera in the community. ${ }^{13}$

It has been suggested that better-quality photographs could be achieved with the non-mydriatic fundus camera if, despite its name, it were used in conjunction with dilating drops. We consider that there are definite advantages in avoiding the routine use of mydriatics. In young patients even short-acting tropicamide causes several hours of inconvenient paralysis of accommodation and blurred near vision. Increased ocular spherical aberration may also diminish distance acuity and prevent safe driving. In our hospital the camera is located within the informal environment of the Diabetic Day Unit. We wish to cultivate a 'drop-in centre' community facility ethos amongst local diabetic patients regarding the unit and the services it offers. We feel that a simple photograph of the eyes helps towards this, but that instilling eye drops might impede take-up of the offer of screening. Nevertheless in an attempt to improve the overall standard of photographic quality it may be worth selectively dilating patients aged 
over 55 years amongst whom poorer-quality photographs are more likely to occur otherwise. Since such patients are presbyopic they are unlikely to be troubled by pharmacological loss of accommodation.

We have shown that a high standard of photographic quality can be achieved with the non-mydriatic fundus camera. We believe that housing the camera in an apt hospital location and employing a motivated and long-term designated team to run the programme has been essential in this. However, like the other available screening modalities for diabetic retinopathy, the non-mydriatic camera is not perfect and there is room for improvement.

Statistical advice was provided by Dr. R. Pickering, Department of Medical Statistics and Computing, University of Southampton.

Key words: Diabetic retinopathy, Non-mydriatic fundus camera, Photography, Screening.

\section{REFERENCES}

1. Rohan TE, Frost DF, Wald NJ. Prevention of blindness by screening for diabetic retinopathy: a quantitative assessment. BMJ 1989;299:1198-201.

2. Bron AJ. Screening for treatable diabetic retinopathy. BMJ 1985;290:1026-6.

3. Cheng H, Franklin S. Screening for sight-threatening diabetic retinopathy. Practitioner 1987;231:1545-8.

4. Mayon-White VA, Jenkins LM, Knight AH. A district screening and treatment service for diabetic retinopathy. Diabetic Med 1986;3:253-6.

5. Burns-Cox CJ, Dean Hart JC. Screening of diabetics for retinopathy by ophthalmic opticians. BMJ 1985;290:1052-4.

6. Ryder REJ, Vora JP, Atiea JA, Owens DR, Hayes TM, Young S. Possible new method to improve detection of dia- betic retinopathy: Polaroid non-mydriatic retinal photography. BMJ 1985;291:1256-7.

7. Ryder REJ, Young S, Vora JP, Atiea JA, Owens DR, Hayes TM. Screening for diabetic retinopathy using Polaroid retinal photography through undilated pupils. Practical Diabetes 1985;2(5):34-9.

8. Williams R, Nussey S, Humphry R, Thompson G. Assessment of non-mydriatic fundus photography in detection of diabetic retinopathy. BMJ 1986;293:1140-2.

9. Jones D, Dolben J, Owens DR, Vora JP, Young S, Creagh FM. Non-mydriatic Polaroid photography in screening for diabetic retinopathy: evaluation in a clinical setting. BMJ 1988;296: 1029-30.

10. Mohan R, Kohner EM, Aldington SJ, Nijhar I, Mohan V, Mather HN. Evaluation of a non-mydriatic camera in Indian and European diabetic patients. Br J Ophthalmol 1988;72: 841-5.

11. Rogers D, Bitner-Glindzicz M, Harris C, Yudkin JS. Nonmydriatic retinal photography as a screening service for General Practitioners. Diabetic Med 1990;7:165-7.

12. Taylor R, Lovelock L, Tunbridge WMG, Alberti KGMM, Brackenridge RG, Stephenson P, et al. Comparison of nonmydriatic retinal photography with ophthalmoscopy in 2159 patients: mobile retinal camera study. BMJ 1990;301: 1243-7.

13. Higgs ER, Harney BA, Kelleher A, Reckless JPD. Detection of diabetic retinopathy in the community using a nonmydriatic camera. Diabetic Med 1991;8:551-5.

14. Leese GP, Newton RW, Jung RT, Haining W, Ellingford A. Screening for diabetic retinopathy in a widely spaced population using non-mydriatic fundus photography in a mobile unit. Diabetic Med 1992;9:459-62.

15. Buxton MJ, Sculpher MJ, Ferguson BA, Humphreys JE, Altman DJ, Spiegelhalter DJ, et al. Screening for treatable diabetic retinopathy: a comparison of different methods. Diabetic Med 1991;8:371-7.

16. Heaven CJ, Cansfield J, Shaw KM. A screening programme for diabetic retinopathy. Practical Diabetes 1992;9 (2):43-5. 